\title{
Effects of partial replacement of silica with surface modified nanocrystalline cellulose on properties of natural rubber nanocomposites
}

\author{
S. H. Xu, J. Gu*, Y. F. Luo, D. M. Jia \\ College of Materials science and Engineering, South China University of Technology, Guangzhou 510640, China
}

Received 17 April 2011; accepted in revised form 11 July 2011

\begin{abstract}
Nanocrystalline cellulose was modified by 3-aminopropyl-triethoxysilane (KH550). The modified nanocrystalline cellulose (MNCC) was further investigated to partially replace silica in natural rubber (NR) composites via coagulation. NR/MNCC/silica and NR/nanocrystalline cellulose (NCC)/silica nanocomposites were prepared. Through the comparison of vulcanization characteristics, processing properties of compounds and mechanical properties, compression fatigue properties, dynamic mechanical performance of NR/MNCC/silica and NR/NCC/silica nanocomposites, MNCC was proved to be more efficient than NCC. MNCC could activate the vulcanization process, suppress Payne effect, increase $300 \%$ modulus, tear strength and hardness, and reduce the heat build-up and compression set. Moreover, fine MNCC dispersion and strong interfacial interaction were achieved in NR/MNCC/silica nanocomposites. The observed reinforcement effects were evaluated based on the results of apparent crosslinking density $\left(V_{\mathrm{r}}\right)$, thermo-gravimetric (TG) and scanning electron microscopic (SEM) analyses of NR/MNCC/silica in comparison with NR/NCC/silica nanocomposites.
\end{abstract}

Keywords: rubber, nanocrystalline cellulose, silica, reinforcement, KH550

\section{Introduction}

Silica has always been used as an important rubber reinforcing filler for its excellent reinforcing effect [1-3], the capability of reducing the heat build-up $[4,5]$ and rolling resistance of rubber $[6,7]$. Therefore, silica as an indispensable filler in rubber products has been widely used and investigated. However, its high density $\left(2.5 \mathrm{~g} / \mathrm{cm}^{3}\right.$ compared to general raw rubber $1.1 \mathrm{~g} / \mathrm{cm}^{3}$ ) makes the density of silica filled vulcanized rubber relatively high, thus reversing an important property of polymer materials, namely their low density. Moreover, silica leads to a number of shortcomings such as long processing time, high energy consumption and environment pollution during processing. Therefore, it is a quite urgent issue for researchers to find some new materials which can overcome above mentioned shortcomings and partially replace silica applications in rubber.

Natural cellulose has similar chemical composition to starch $[8,9]$. When used as a macromolecular rubber-reinforcing fillers, they exhibit many advantages like renewability, biodegradability, easy to process, low density, low cost, energy conservation and environmental friendliness. In addition, compared to starch, a number of improved properties such as observably increased mechanical properties $[10,12,16]$, improved hot air aging performance [13], processing properties [11, 14], dynamic mechanical performance and reduced heat build-up [14] have been achieved in the applications of MCC and $\mathrm{NCC}$ derived from natural cellulose in rubber.

\footnotetext{
${ }^{*}$ Corresponding author, e-mail: psjgu@scut.edu.cn
}

(c) BME-PT 
Therefore, MCC and NCC have drawn increasing interest in recent years [10-18]. However, the nature of numerous hydroxyl groups and easy aggregation of NCC make it difficult to disperse NCC finely in a rubber matrix. Surface modification [19-22] and chemical grafting [23-26] have been used in the modifications of NCC. The main objectives of the modifications are improving the NCC dispersion and reinforcing the interfacial strength between NCC and rubber. Among them, surface modification is simple and one can select different surfactants according to needs.

Many researches have studied the applications of MCC and NCC in plastics matrices [27-31], while in rubber [10-16], there are only a few publications. Most of them mainly studied the influence of adding MCC [14] or chemical modified NCC [13, $15]$ on the structure and properties of rubber. Three kinds of coupling agents, namely, phenyl isocyanate (PI), alkenyl succinic anhydride (ASA), and 3-isopropenyl- $\alpha, \alpha^{\prime}$-dimethylbenzyl isocyanate (TMI) were applied to chemically modify the surface of chitin whiskers and then prepared a kind of nanocomposite films. Even though there was an increase in filler matrix interaction, this did not contribute to the improvement in the mechanical properties of the resulting nanocomposite. It was concluded that this loss of performance was due to the partial destruction of the three-dimensional network of chitin whiskers assumed to be present in the unmodified composites [15]. Nevertheless, the attempting of applying surface modified NCC to rubber is rarely reported. Recently, the preparation, surface modification [32] of NCC and its applications in rubber [13] were discussed by our research group.

In this paper, NCC was firstly modified by KH550 and used as filler to partially replace silica. Two types of compounds and nanocomposites, NR/NCC/ silica and NR/MNCC/silica were prepared by direct compounding with NRL, respectively. Properties and morphology of these compounds nanocomposites and corresponding NCC were investigated. The observed reinforcement effect of MNCC on NR/silica nanocomposites was discussed. The result exhibit that the way of using KH550 to modify NCC is simpler and more efficient than other methods. The comprehensive properties of NR/MNCC/silica composites have been largely improved, because KH550 can react with both NCC and rubber. Therefore, it makes a very real sense using the NCC as a new energy saving filler partly replacing silica.

\section{Experiment \\ 2.1. Materials}

Natural rubber latex (NRL) with $59.4 \mathrm{wt} \%$ solid contents was purchased from $11^{\text {th }}$ Rubber Plant, Guangzhou, China. Microcrystalline Cellulose (MCC) was provided by Gaoyao Gaoli Additives Corp., Guangdong, China. Precipitated silica with trade name of ZQ356 was obtained from Zhuzhou xinglong chemical industrial Co., LTD., Hunan, China. KH550 was provided by Shuguang chemicals group Co., LTD. Nanjing, China. Other reagents and ingredients were commercially available and were used as received.

\subsection{Preparation of NCC suspension}

$\mathrm{MCC}$ was stirred for $30 \mathrm{~min}$ at $45^{\circ} \mathrm{C}$ with $64 \mathrm{wt} \%$ $\mathrm{H}_{2} \mathrm{SO}_{4}$. The amount of $\mathrm{H} 2 \mathrm{SO} 4$ was set to $10 \mathrm{ml}$ per $1 \mathrm{~g}$ MCC. After hydrolysis, the suspension was repeatedly washed with distilled water by centrifugation until the $\mathrm{pH}$ approached 7.0. Then $1.0 \mathrm{wt} \%$ $\mathrm{NaOH}$ solution was added to the suspension with stirring to adjust the suspension $\mathrm{pH}$ to 7.0 and then kept at room temperature for $24 \mathrm{~h}$.

\subsection{Preparation of MNCC suspension}

NCC was mixed with ethanol (95 wt\%) under stirring at ambient temperature. After an addition of KH550, the reaction lasted $2 \mathrm{~h}$ under refluxing. MNCC was then obtained after a filtering and dried. Deionized water was added to the final product to prepare a MNCC suspension.

\subsection{Preparation of NR/NCC and NR/MNCC compounds}

NCC suspension or MNCC suspension was mixed with NRL and stirred vigorously at room temperature for $15 \mathrm{~min}$, and then $10 \mathrm{wt} \% \mathrm{CaCl}_{2}$ solution was added to co-coagulate the mixture. The coagulum was washed by water and then dried in oven at $70^{\circ} \mathrm{C}$ until a constant weight was obtained.

\subsection{Preparation of NR/NCC/silica and NR/MNCC/silica nanocomposites}

NR/NCC/silica and NR/MNCC/silica nanocomposites were prepared by the following procedure. Basic formulation of all compounds is shown in 
Table 1. compounding formulation (phr)

\begin{tabular}{|c|c|c|c|}
\hline & NCC & Silica & KH550 \\
\hline U-1 & 0 & 30 & 0 \\
\hline U-2 & 5 & 25 & 0 \\
\hline U-3 & 10 & 20 & 0 \\
\hline U-4 & 15 & 15 & 0 \\
\hline U-5 & 20 & 10 & 0 \\
\hline U-6 & 25 & 5 & 0 \\
\hline M-1 & 0 & 30 & 0.9 \\
\hline M-2 & 5 & 25 & 0.9 \\
\hline M-3 & 10 & 20 & 0.9 \\
\hline M-4 & 15 & 15 & 0.9 \\
\hline M-5 & 20 & 10 & 0.9 \\
\hline M-6 & 25 & 5 & 0.9 \\
\hline
\end{tabular}

Note: The other ingredients of U-1-U-6 and M-1-M-6 are as following(phr): NR 100, Sulphur 2, Zinc oxide 5, Stearic acid 2, N-cyclohexyl-2-benzothiazole 1.5, sulfenamide2,2'dibenzothiazole disulfide 0.5 , N-isopropyl-N'-phenyl-pphenylenediamine 1.5 .

Table 1. Compounding was carried out on a two-roll mill by the well-known method. The rubber compound sheets were compressed and vulcanized at $143^{\circ} \mathrm{C}$ for $t_{\mathrm{c} 90}$.

\subsection{The morphology analysis of NCC}

NCC and silica suspension was diluted and then treated by ultrasound. Transmission electron microscopy (TEM) observations were made with a Philip Tecnai 12 TEM (Eindhoven, Netherlands) electron microscope. A droplet of a treated suspension of NCC and silica was deposited and allowed to dry on a copper mesh.

\subsection{Characterization of NR/NCC/silica and NR/MNCC/silica compounds}

Vulcanization parameters and curing curve for NR/ $\mathrm{NCC} /$ silica and $\mathrm{NR} / \mathrm{MNCC} /$ silica compounds were tested in a standard testing procedure according to ISO 3417:1991 using a U-CAN UR2030 vulcameter (U-CAN DYNATEX INC, Taiwan).

The strain dependence of $G^{\prime}$ for NR/NCC/silica and $\mathrm{NR} / \mathrm{MNCC} /$ silica compounds was determined by RPA(GÖTTFERT VISCO - ELASTOGRAPH, Germany). The condition of measurement is at a frequency of $1 \mathrm{~Hz}$, a temperature of $60^{\circ} \mathrm{C}$, and a strain range from 1.4 to $420 \%$.

\subsection{Properties of $\mathrm{NR} / \mathrm{NCC} /$ silica and NR/MNCC/silica nanocomposites tests}

The mechanical properties, such as modulus at $300 \%$, tensile strength, and tear strength, were meas- ured according to ISO/DIS37-1994 and ISO 34-11994 specifications. U-CAN electron tensile testing machine (U-CAN DYNATEX INC, Taiwan) was used with the crosshead speed of $500 \mathrm{~mm} / \mathrm{min}$. Three to five specimens were measured for each particular sample and the average values were reported with standard deviation showing the error range. The hardness of the samples was measured by a Shore A Durometer.

To study the heat build-up and compression set at dynamic situation of these materials, U-CAN UD380 (U-CAN DYNATEX Inc., Taiwan) was used according to ISO 4666/3-1982. Cylindrical rubber specimens $(25 \mathrm{~mm}$ in height and $17.5 \mathrm{~mm}$ in diameter) were subjected to repeated compression using a grip. The frequency of loading was $30 \mathrm{~Hz}$, and the stroke (double amplitude) of imposed oscillation was $4.45 \mathrm{~mm}$. The severity of the test was adjusted by varying the static compressive load applied to the sample, and compressive loadings of $24.5 \mathrm{~kg}$ were treated. The test procedures were terminated when the sample carried out about 25 min constant load or constant displacement fatigue. Three specimens were measured for each particular sample and the average values were reported with standard deviation showing the error range.

The dynamic mechanical analysis of the samples was obtained by using an EPLEXOR 500N DMA Analyzer (GABO Corp. Germany). The specimens were analyzed in tensile mode at a constant frequency of $10 \mathrm{~Hz}$, and a temperature range from -80 to $10^{\circ} \mathrm{C}$ at a heating rate of $2.5^{\circ} \mathrm{C} / \mathrm{min}$. Mechanical loss factor $(\tan \delta)$ was measured as a function of temperature for the samples under identical conditions.

\subsection{Structure of $\mathrm{NR} / \mathrm{NCC} /$ silica and NR/MNCC/silica nanocomposites [33]}

Crosslinking density was determined by equilibrium swelling method. The samples were swollen in hexane at room temperature to an equilibrium state and then removed from the solvent, and the hexane on the surface was quickly blotted off with tissue paper. The samples were immediately weighed on an analytical balance to the tolerance of $1 \mathrm{mg}$ and then dried at vacuum. Assuming the mass loss of the rubber during swelling is the same for all the samples, the volume fraction of rubber in swollen gel $\left(V_{\mathrm{r}}\right)$, which was used to represent the crosslink- 
ing density of the vulcanizates, was determined by the Equation (1):

$$
V_{\mathrm{r}}=\frac{1}{1+\left(\frac{m_{\mathrm{b}}}{m_{\mathrm{a}}}-1\right) \cdot \frac{\rho_{\mathrm{r}}}{\alpha \rho_{\mathrm{s}}}}
$$

where $m_{\mathrm{a}}$ and $m_{\mathrm{b}}$ is the sample masses before and after swelling, $\rho_{\mathrm{r}}$ and $\rho_{\mathrm{s}}$ is the density of rubber and solvent, respectively, and $\alpha$ is the mass fraction of rubber in the vulcanizates.

The TGA of vulcanized rubber were detected on TGAR5000IR TA Analyzer produced by TA Corp. (USA). Test condition: heating rate of $10^{\circ} \mathrm{C} / \mathrm{min}$, temperature range from room temperature to $600^{\circ} \mathrm{C}$, nitrogen atmosphere.

Scanning electron microscopy (SEM) was performed to investigate the morphology of the NR/ NCC, NR/MNCC and NR/MNCC/silica and nanocomposites with a LEO 1530 VP (LEO Company, Germany) SEM. The specimens were stretch-fractured, and then fractured, mounted, coated with thin film of gold, and observed. SEM micrographs were obtained using $5 \mathrm{kV}$.

\section{Results and discussion}

\subsection{Influence of MNCC on properties of NR/MNCC/silica compounds}

Vulcanization curves and parameters of the compounds are shown in Figure 1 and Table 2. It can be seen that $t_{\mathrm{c} 90}$ exhibit constant decrease trends as the amount of NCC or MNCC increased from 5 to $25 \mathrm{phr}$. Meanwhile, the vulcanization rate constant $k$ was gradually increased. The results prove that the addition of NCC or MNCC can promote rubber vulcanization and accelerate vulcanization rate [14]. As seen from Table 2, $k$ was raised with the same

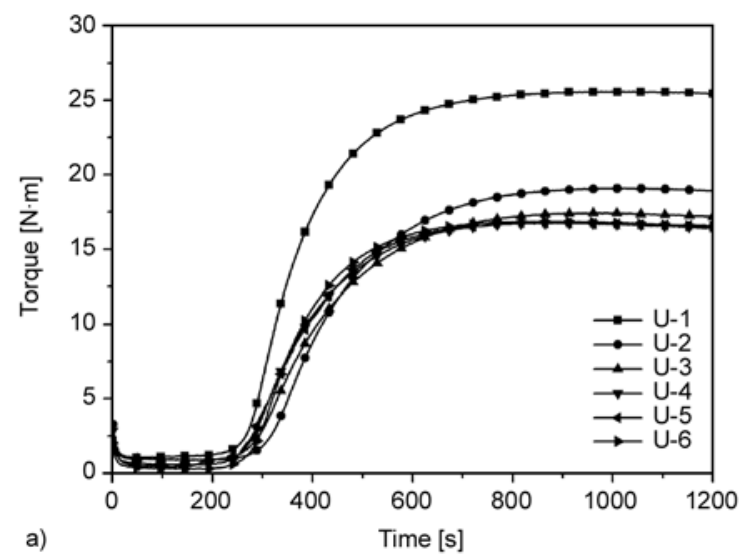

Table 2. Curing parameters of NR/NCC/silica and NR/ MNCC/silica compounds $\left(143^{\circ} \mathrm{C}\right)$

\begin{tabular}{|c|c|c|c|c|c|}
\hline $\begin{array}{c}\text { Sample } \\
\text { numbers }\end{array}$ & $\begin{array}{c}\mathbf{t}_{\mathbf{c 1 0}} \\
{[\mathbf{s}]}\end{array}$ & $\begin{array}{c}\mathbf{t}_{\mathbf{c 9 0}} \\
{[\mathbf{s}]}\end{array}$ & $\begin{array}{c}\mathbf{M}_{\mathbf{L}} \\
{[\mathbf{d N} \cdot \mathbf{m}]}\end{array}$ & $\begin{array}{c}\mathbf{M}_{\mathbf{H}} \\
{[\mathbf{d N} \cdot \mathbf{m}]}\end{array}$ & $\begin{array}{c}\mathbf{k} \\
{\left[\mathbf{m i n}^{-1} \mathbf{]}\right.}\end{array}$ \\
\hline $\mathrm{U}-1$ & 279 & 504 & 1.04 & 25.57 & 26.7 \\
\hline $\mathrm{U}-2$ & 320 & 646 & 0.87 & 19.08 & 18.4 \\
\hline $\mathrm{U}-3$ & 293 & 623 & 0.87 & 17.41 & 18.2 \\
\hline $\mathrm{U}-4$ & 276 & 565 & 0.56 & 16.77 & 20.8 \\
\hline U-5 & 269 & 554 & 0.42 & 16.79 & 21.1 \\
\hline $\mathrm{U}-6$ & 286 & 534 & 0.28 & 16.86 & 24.2 \\
\hline M-1 & 205 & 312 & 2.83 & 29.02 & 56.1 \\
\hline M-2 & 235 & 368 & 2.57 & 29.00 & 45.1 \\
\hline M-3 & 229 & 360 & 2.27 & 28.42 & 45.8 \\
\hline M-4 & 207 & 326 & 2.21 & 30.75 & 50.4 \\
\hline M-5 & 191 & 303 & 2.21 & 27.76 & 53.6 \\
\hline M-6 & 157 & 267 & 2.56 & 27.18 & 54.5 \\
\hline
\end{tabular}

Vulcanization rate constant, $k=100 /\left(t_{\mathrm{c} 90}-t_{\mathrm{c} 10}\right)\left[\mathrm{min}^{-1}\right]$

amount MNCC compared to NCC. This is because KH550 can adsorb activator, promoting agents and sulphur, leading to activation of vulcanization. $M_{\mathrm{L}}$ and $M_{\mathrm{H}}$ of the compounds were decreased as the increasing of NCC. It is probably owing to the fact that NCC can act as a plasticizer, lead to better liquidity and improve the processing performance of the compounds [14]. However, $M_{\mathrm{L}}$ and $M_{\mathrm{H}}$ were nearly unchanged with the increasing of MNCC, but much higher than those of adding NCC. These are attributed to that KH550 can chemically react with both NCC and rubber, improve filler-rubber interactions therefore increase crosslinking density of nanocomposites. The modification effect of KH550 was confirmed by the following crosslinking density analysis results.

Figure 2 shows a plot of elastic modulus versus the logarithm of strain of unvulcanized compounds. As can be seen, the modulus of the compounds decreases gradually and shows a typical nonlinear behavior

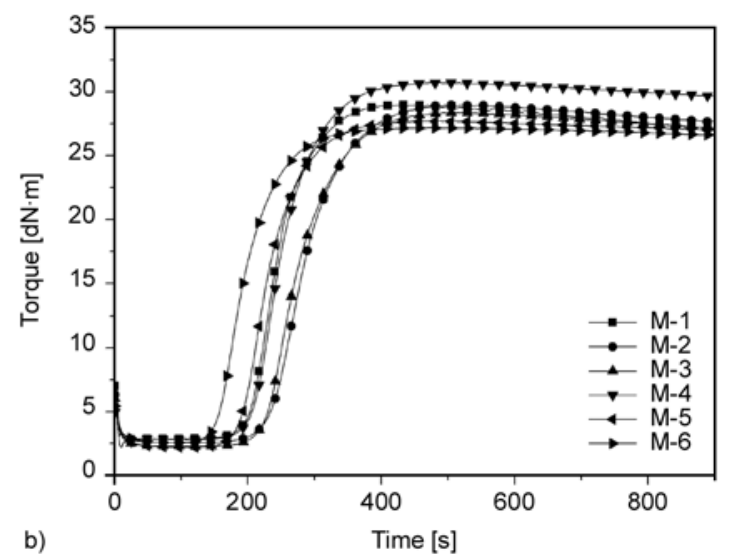

Figure 1. Curing curves of (a) NR/NCC/silica and (b) NR/MNCC/silica compounds $\left(143^{\circ} \mathrm{C}\right)$ 

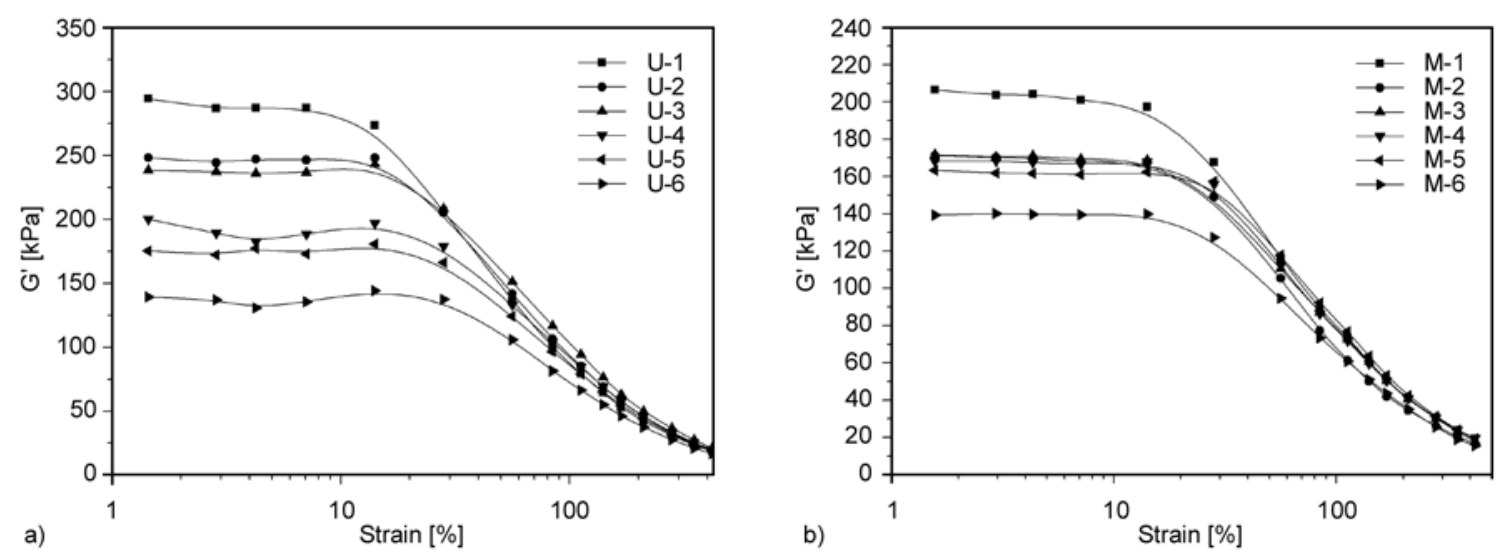

Figure 2. $G^{\prime}$-Strain curves of (a) NR/NCC/silica and (b) NR/MNCC/silica compounds

with increasing strain, which is generally termed the 'Payne effect'. It is also observed that the 'Payne effect' obviously decreased with the NCC or MNCC increasing and changed significantly with the same amount of NCC compared to MNCC. The Payne effect is mainly related to the filler network formed in the rubber matrix which has been widely accepted. The rubber trapped or caged in the filler network would at least be partially 'dead,' behaving like a filler. Therefore, the effective volume of the silica would increase substantially upon filler networking. However, with the addition of NCC, especially MNCC, the networking of silica is weakened and so is the Payne effect. Likely because the addition of NCC or MNCC can reduce the interaction of filler aggregates and the degree of the network, enhance the interaction between NR and filler, and improving the processing performance of compounds [14].

\subsection{Influence of MNCC on structure and properties of $\mathrm{NR} / \mathrm{MNCC} /$ silica nanocomposites}

The mechanical properties of nanocomposites with different NCC or MNCC were examined and shown in Figure 3, the total amount of NCC or MNCC and silica was $30 \mathrm{phr}$. It can be seen that the tensile strength, elongation at break and tear strength were almost kept constant with the increasing of NCC or MNCC. While the modulus at 300\% increased significantly. This improvement may be explained by the high stiffness and rod-like structure of NCC, whereas a significant increase of Young's modulus was achieved by using NCC to reinforce nanocomposites, which is consistent with the reports by Cao et al. [30] and Ten et al. [31]. It can also be observed that the mechanical properties of nanocomposites were obviously improved by using MNCC compare to NCC, especially on $300 \%$ modulus, tear strength and hardness [34]. When the NCC was modified by KH550, more uniform distribution of MNCC particles in the NR matrix was obtained (as shown in the following SEM photograph) as well as the stronger interfacial interaction between rubber and fillers, which would allow an improvement of mechanical properties of the nanocomposites. And these results were in accordance with the following crosslinking density analysis.

As shown in Figure 4, heat build-up and compression set at dynamic compression of nanocomposites were significantly decreased with the increasing NCC or MNCC. Moreover, with the addition of MNCC, they show further decreases than with NCC. It is believed that the heat build-up of reinforced rubber is mainly came from lag, which is caused by deformation and reorganization of secondary aggregates of filler under the action of high gravitational field in the rubber. The better the dispersion of filler, the lower the heat build-up and the smaller the deformation $[4,5]$. Heat build-up and compression set were reduced with the increasing of NCC content because the hydroxyl groups on the surface of NCC were less than on silica, which were easily agglomerated. It is consistent with the report results of Bai and $\mathrm{Li}$ [14]. Moreover, the heat buildup and compression set are also due to the friction between filler and matrix and between filler particles [35]. As the distribution of MNCC gets even, the agglomeration tendency between particles decreases (as shown in the following SEM photographs) which weakens the filler network. Thus, it reduces 

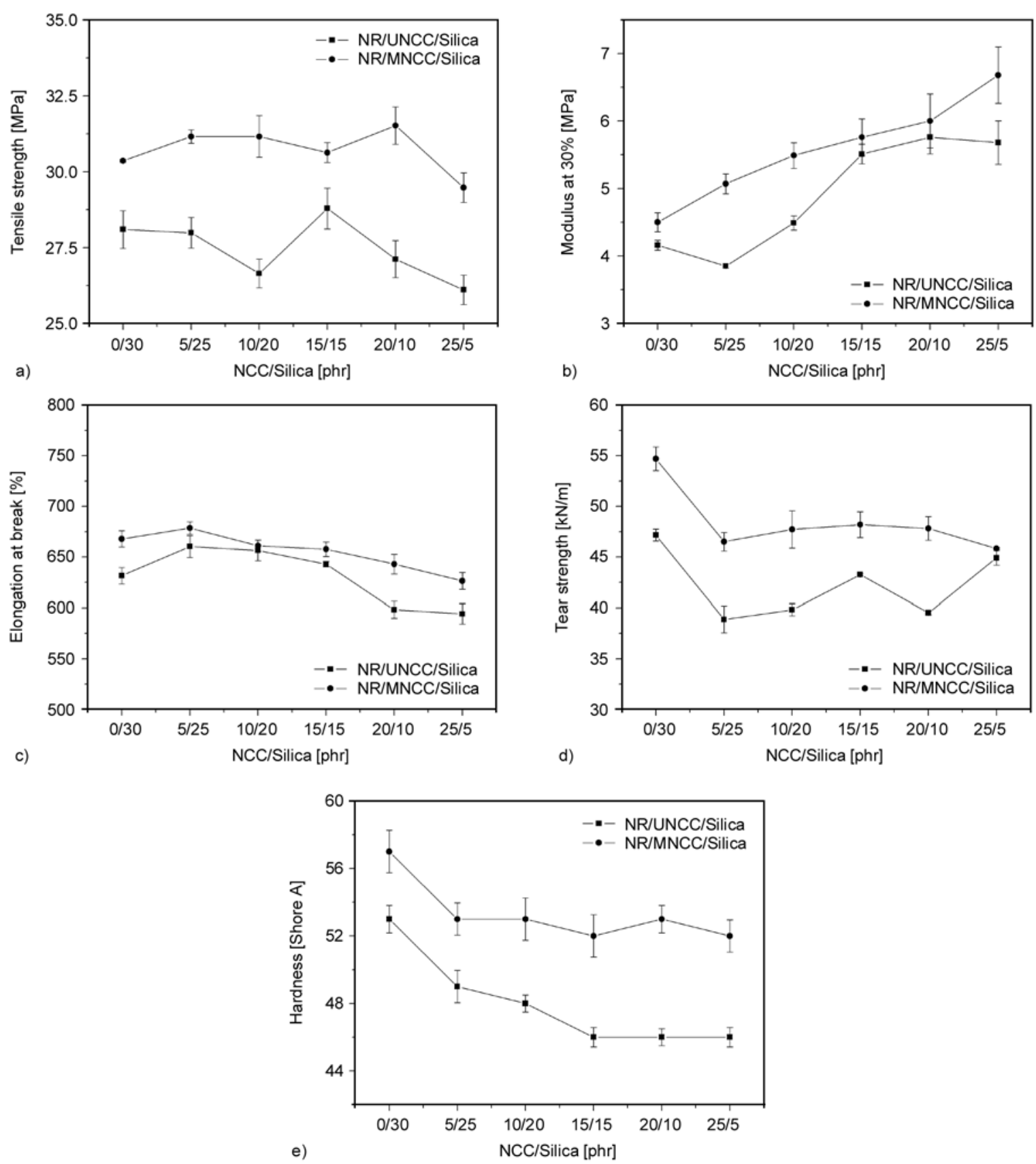

Figure 3. Variation of mechanical properties of NR/NCC/silica and NR/MNCC/silica nanocomposites via NCC/silica content. The values are given by average and the error ranges are given by standard deviation as evaluated by results from 3-5 parallel samples. (a) Tensile strength, (b) 300\% modulus, (c) elongation at break, (d) tear strength and (e) hardness (Shore A). Lines are to guide the eye.

the repeatedly breakdown and reforming of the network, and leads to lower heat build-up and compression set.

It is well-known that the rolling resistance and skid resistance of tires play an important role in the running of an automotive. From the viscoelastic property point of view, an ideal material, which is able to meet the requirements of a high-performance tire, should give a lower $\tan \delta$ at $60^{\circ} \mathrm{C}$ and demon- strate high lag at $0^{\circ} \mathrm{C}$ to reduce rolling resistance and obtain high-skid resistance. Figure 5 and Table 3 show $\tan \delta$ - $T$ curves and its data of nanocomposites. It can be seen that glass transition temperature $\left(T_{\mathrm{g}}\right)$ was nearly unchanged and the $\tan \delta$ peak of nanocomposites became much higher as the increasing of NCC or MNCC. Moreover, the $\tan \delta$ peak was further enhanced when NCC was modified. This can be explained by the rubber shell theory [36]. NCC can 

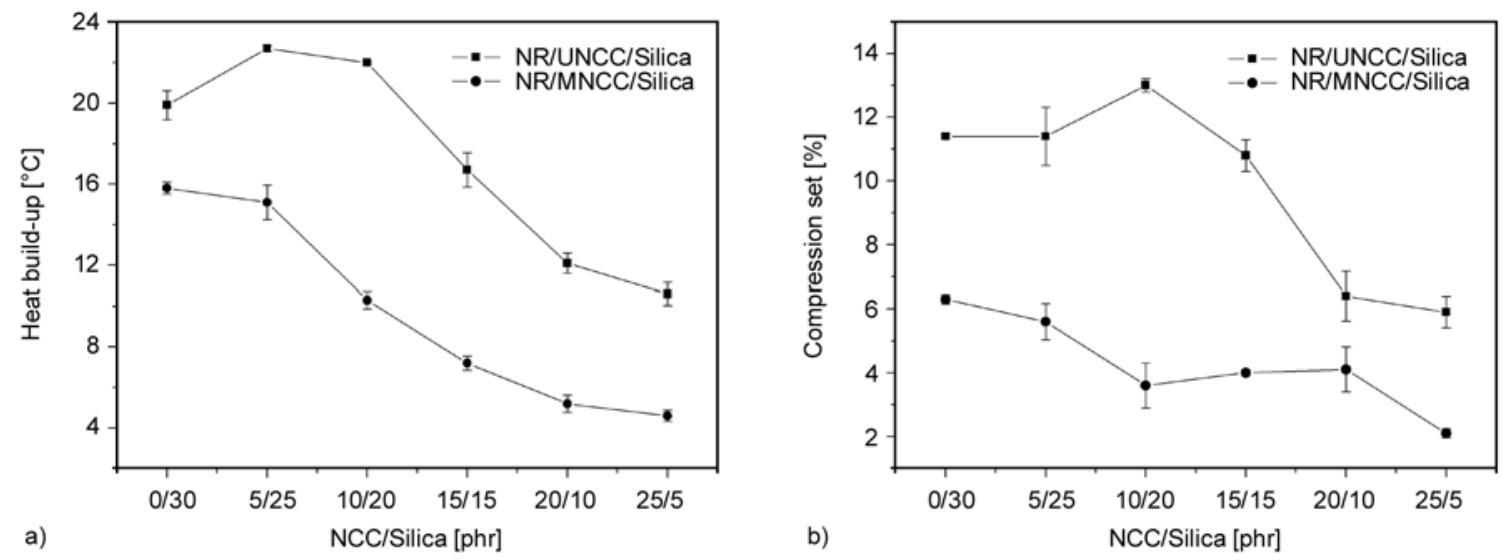

Figure 4. The heat effect of the compression fatigue of the NR/NCC/silica and NR/MNCC/silica nanocomposites via $\mathrm{NCC} /$ silica content. The values are given by average and the error ranges are given by standard deviation as evaluated by results from 3 parallel samples. (a) Heat build-up and (b) compression set. Lines are to guide the eye.
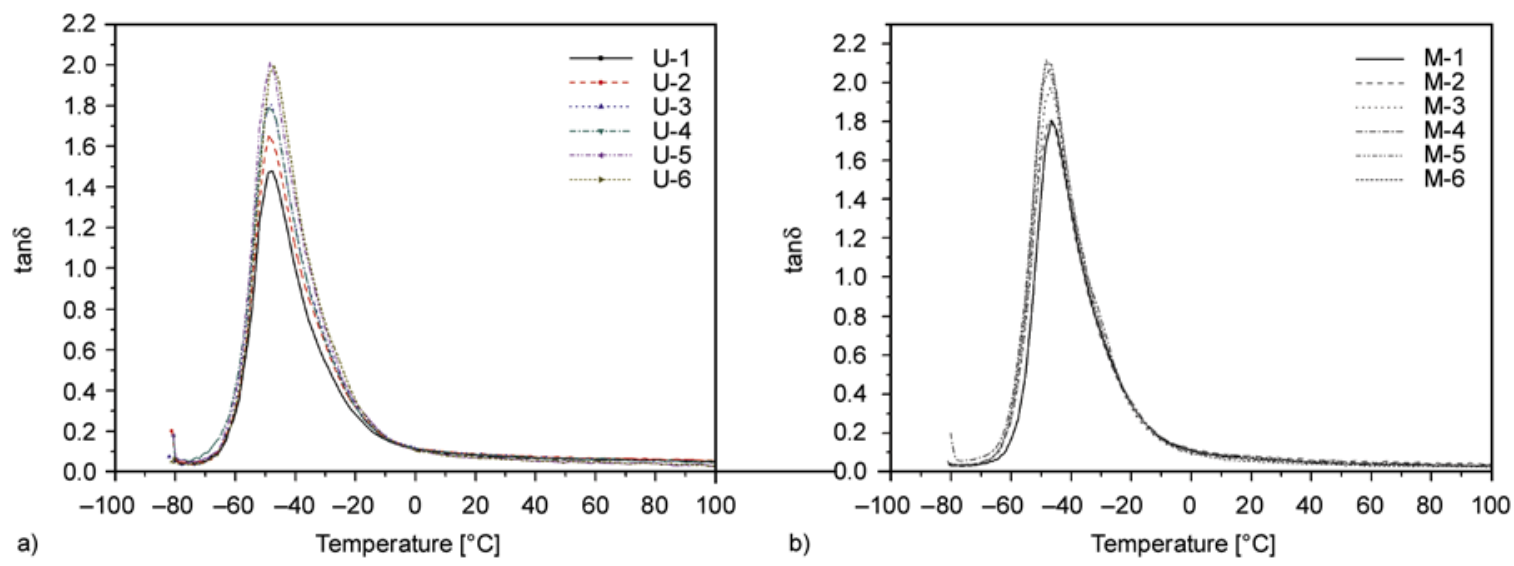

Figure 5. $\tan \delta$-T curves of (a) NR/NCC/silica and (b) NR/MNCC/silica nanocomposites

physically absorb rubber chain due to the large surface area to volume ratio. The bound rubber chains that are absorbed by NCC, are still in the glassy state while the other rubber chains stay in the elastic state. With the help of KH550, more rubber chains can be chemically absorbed by NCC because of the

Table 3. Data of the $\tan \delta$ - $T$ curves of NR/NCC/silica nanocomposites and $\mathrm{NR} / \mathrm{MNCC} /$ silica nanocomposites

\begin{tabular}{|c|c|c|c|}
\hline $\begin{array}{c}\text { Sample } \\
\text { numbers }\end{array}$ & $\begin{array}{c}\mathbf{T}_{\mathbf{g}} \\
{\left[{ }^{\circ} \mathbf{C}\right]}\end{array}$ & $\mathbf{0}^{\circ} \mathbf{C}-\tan \boldsymbol{\delta}$ & $\mathbf{6 0}^{\circ} \mathbf{C}-\tan \boldsymbol{\delta}$ \\
\hline $\mathrm{U}-1$ & -47.7 & 0.115 & 0.060 \\
\hline $\mathrm{U}-2$ & -49.0 & 0.116 & 0.064 \\
\hline $\mathrm{U}-3$ & -47.9 & 0.119 & 0.062 \\
\hline $\mathrm{U}-4$ & -49.0 & 0.113 & 0.060 \\
\hline $\mathrm{U}-5$ & -48.5 & 0.111 & 0.049 \\
\hline $\mathrm{U}-6$ & -47.2 & 0.103 & 0.047 \\
\hline $\mathrm{M}-1$ & -46.5 & 0.110 & 0.040 \\
\hline $\mathrm{M}-2$ & -47.5 & 0.123 & 0.046 \\
\hline $\mathrm{M}-3$ & -46.8 & 0.095 & 0.037 \\
\hline $\mathrm{M}-4$ & -47.3 & 0.117 & 0.045 \\
\hline $\mathrm{M}-5$ & -48.4 & 0.104 & 0.039 \\
\hline $\mathrm{M}-6$ & -48.4 & 0.097 & 0.031 \\
\hline
\end{tabular}

reactivity of KH550 with rubber and NCC. Which means more rubber chains will stay in the glass transition area and result in the increase of $\tan \delta$. As can be seen from Table 3, it gets the lower $\tan \delta$ at $60^{\circ} \mathrm{C}$, while the same $\tan \delta$ at $0^{\circ} \mathrm{C}$ when the $\mathrm{NCC}$ was modified. It means that if nanocomposites were applied to the tire tread, low- rolling resistance can be achieved accompanied with maintained skid resistance [6-7, 14].

Apparent crosslink density of nanocomposites is shown in Figure 6. With an increase of NCC, the apparent crosslink density shows a slight downtrend for NR/NCC/silica nanocomposites. However, the apparent crosslink density of NR/MNCC/ silica nanocomposites improved to a different degree. These results are in accordance with that the $\mathrm{MH}$ reduced slightly with adding NCC, while $\mathrm{MH}$ improved when the NCC was modified. Since KH550 can chemically react with both NCC and rubber. The readily hydrolysable ethoxy group $\left(-\mathrm{OC}_{2} \mathrm{H}_{5}\right)$ will react with hydroxyl groups on the 


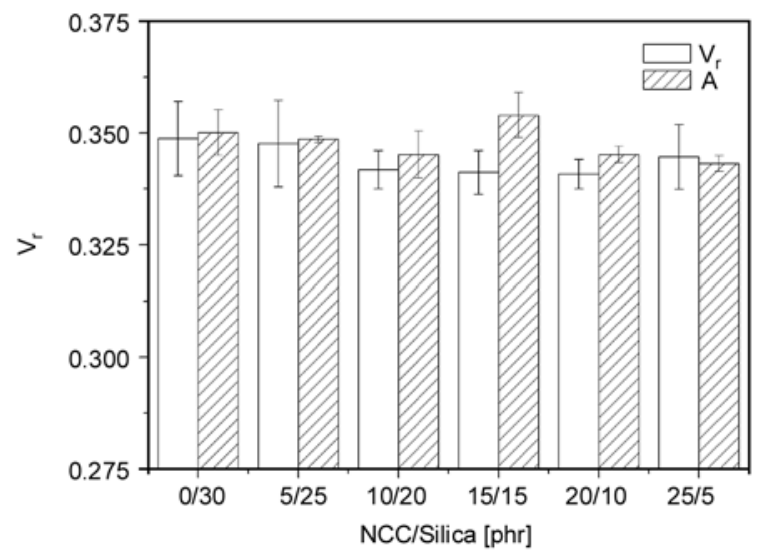

Figure 6. Apparent crosslinking density of NR/NCC/silica and NR/MNCC/silica nanocomposites. The values are given by average and the error ranges are given by standard deviation as evaluated by results from 4 parallel samples. Lines are to guide the eye.

NCC surface to form stable linkage. The $\gamma$-Aminopropyl $\left(-\mathrm{H}_{2} \mathrm{NCH}_{2} \mathrm{CH}_{2}\right)$ can form covalent bonds with the rubber. As a result, KH550 can connect

Table 4. TG data of NR/NCC/silica and NR/MNCC/silica nanocomposites

\begin{tabular}{|c|c|c|c|}
\hline $\begin{array}{c}\text { Sample } \\
\text { numbers }\end{array}$ & $\begin{array}{c}\text { Temperature of } \\
\mathbf{5 \%} \text { weight loss } \\
{\left[{ }^{\circ} \mathbf{C}\right]}\end{array}$ & $\begin{array}{c}\text { Temperature of } \\
\text { maximum weight } \\
\text { loss rate }\left[{ }^{\mathbf{}} \mathbf{C}\right]\end{array}$ & $\begin{array}{c}\text { Residual } \\
\text { mass } \\
{[\%]}\end{array}$ \\
\hline U-1 & 307.86 & 365.69 & 23.05 \\
\hline U-2 & 302.37 & 362.79 & 20.16 \\
\hline U-3 & 295.03 & 362.40 & 17.52 \\
\hline U-4 & 276.37 & 361.96 & 14.75 \\
\hline U-5 & 276.57 & 362.24 & 12.13 \\
\hline U-6 & 266.94 & 362.54 & 9.28 \\
\hline M-1 & 306.68 & 363.06 & 23.29 \\
\hline M-2 & 301.40 & 362.09 & 20.46 \\
\hline M-3 & 296.07 & 361.45 & 17.93 \\
\hline M-4 & 283.68 & 361.49 & 15.1 \\
\hline M-5 & 279.37 & 362.23 & 12.7 \\
\hline M-6 & 280.19 & 361.56 & 9.00 \\
\hline
\end{tabular}

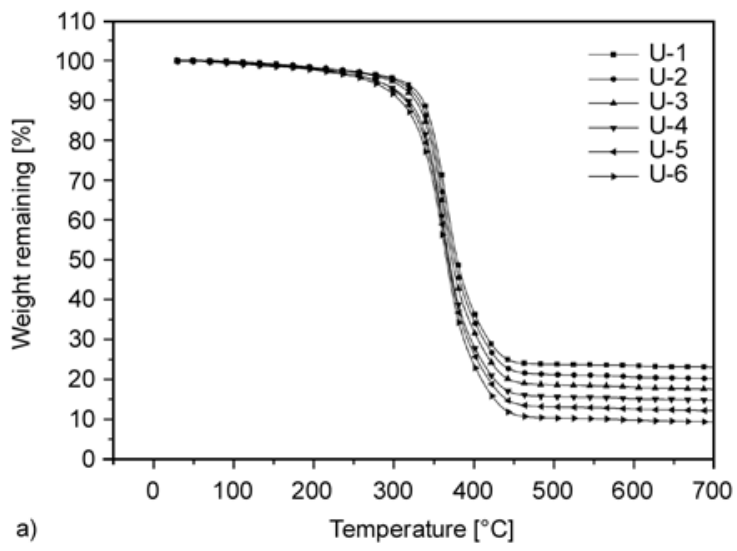

NCC to rubber and increase crosslinking density. The other reason for the increase is that MNCC can reduce the adsorption of accelerator and sulfur by silica. Therefore, KH550 can strengthen the combination of rubber and filler, which shows apparent crosslink density, the mechanical properties and the dynamic mechanical properties increase, accompanied by the reduction of the heat build-up and permanent deformation.

Figure 7 and Table 4 show the TG curves and its data of nanocomposites, respectively. It can be seen that the temperature of maximum weight loss rate was nearly unchanged, while both the temperature at $5 \%$ weight loss and residual mass were gradually decreased with the increases of NCC or MNCC. These results may be originated from that the NCC or MNCC was fully decomposed to the end before $700^{\circ} \mathrm{C}$, but silica was still stable. The temperature at $5 \%$ weight loss as well as residual mass improved as the NCC modified. The reasons can be owing to the fine dispersion of filler and the intensive combination between rubber and filler. The increase of temperature at $5 \%$ weight loss may be due to the strong combination between NR and NCC, whereas the enhancement of residual mass is attributed to the increased combination between NR and silica. These results can also explain the previous conclusion: the heat build-up and permanent deformation are reduced as the increases of mechanical properties and the dynamic mechanical properties.

\subsection{Micrographs of NCC suspension and in the nanocomposites}

\subsubsection{Micrographs of NCC and silica}

Figure 8 shows the TEM micrographs of a dilute suspension of NCC and silica, the length of NCC

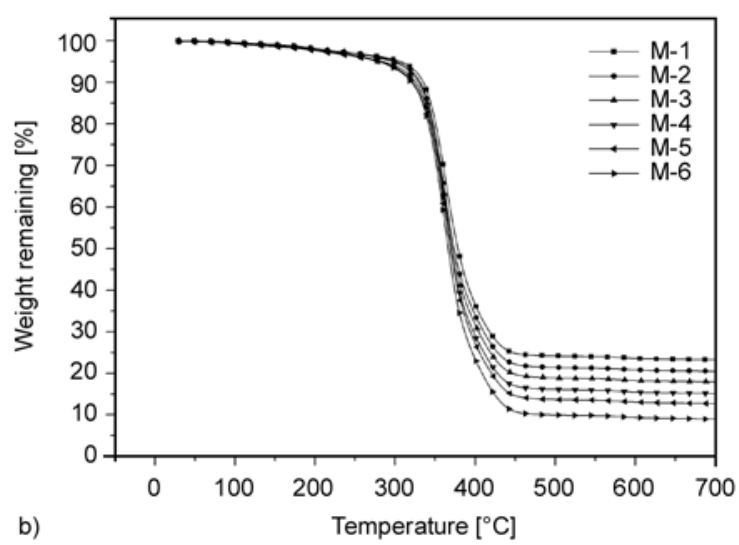

Figure 7. TG curves of NR/NCC/silica and NR/MNCC/silica nanocomposites 


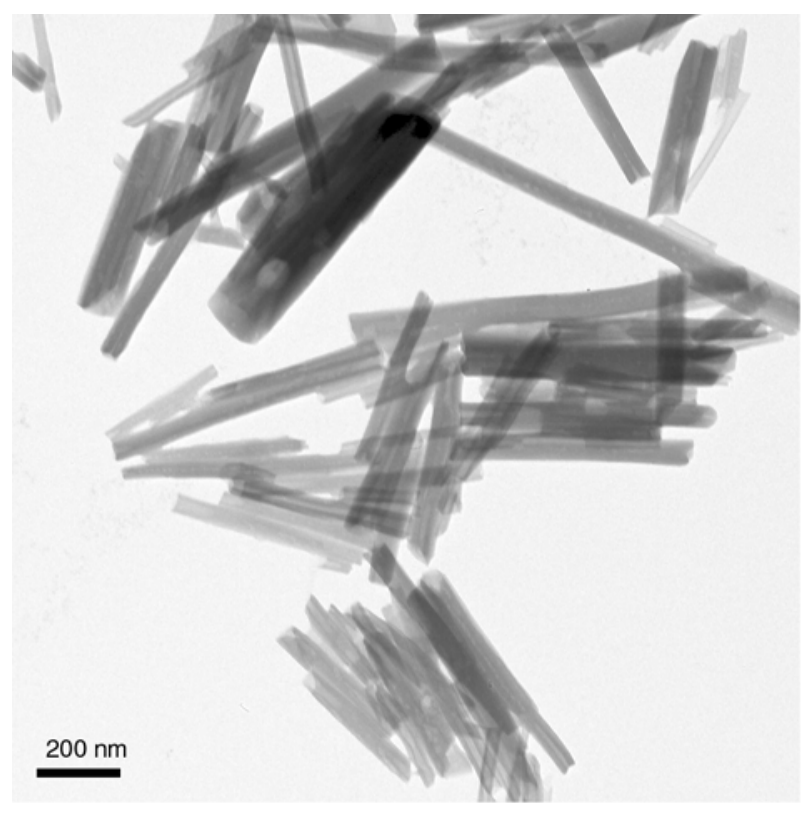

a)

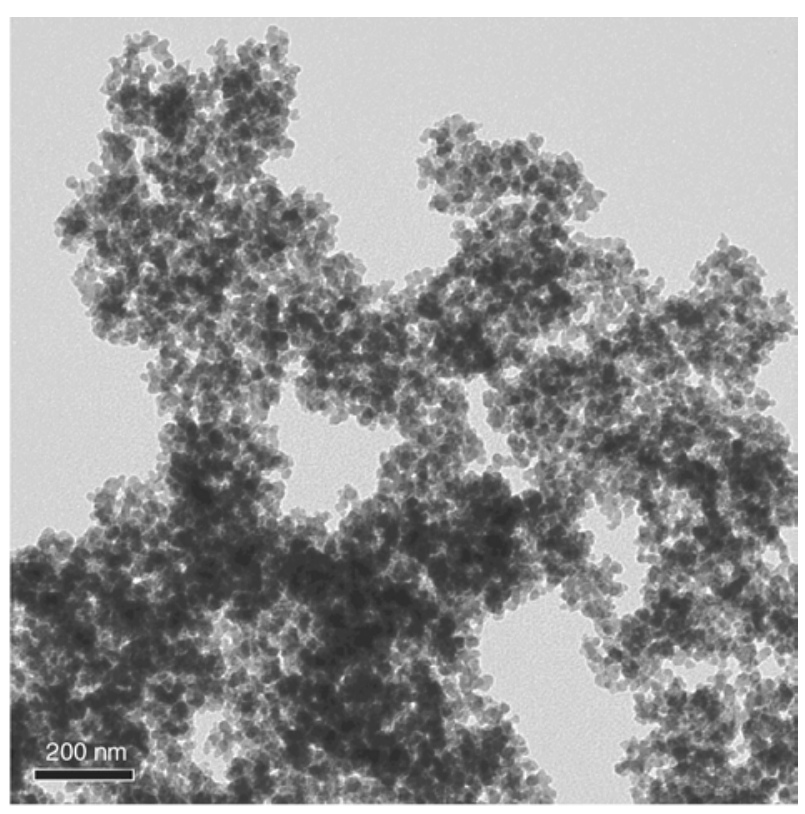

b)

Figure 8. TEM micrographs of (a) NCC and (b) silica suspension

mostly for $300-600 \mathrm{~nm}$, diameter was $40 \sim 60 \mathrm{~nm}$. This confirm results observed by some scholars $[32,37]$. Figure $8 b$ shows that silica original size was below $100 \mathrm{~nm}$, while the silica aggregates reach micro-scales in diameter. Therefore, comparing to silica, NCC aggregates can be easily separated due to the following two factors. Geometrically, the rodlike NCC aggregates are more easily dispersed than the spherial particles. Chemically, these are recognized as with low hydroxyl density on the surface compared with silica.

\subsubsection{Morphology of NCC in the nanocomposites}

Figure 9 shows the SEM photos for the stretch broken surface of the NR/NCC, NR/MNCC ( $0.3 \mathrm{phr}$ KH550 per 10 phr NCC) and NR/MNCC/silica nanocomposites. It can be seen from pictures (a) and (c) that NCC aggregates gathered more seriously, distributed unevenly and lots of them were exposed on the NR matrix surface. There were obvious cracks due to pull out on the cross section, which was relatively smooth. On the contrary, as shown in the picture (b) and (d), MNCC aggregates gathered fewer, dispersed uniformly and most of them embedded in the NR matrix. There were no obvious pull out cracks, which was continuity of cracks. The same phenomenon was shown in pictures (e) and (f) with $10 \mathrm{phr}$ MNCC replacing silica.
These results indicated that the addition of MNCC reinforced the bonding between rubber matrix and filler and led to more firmly. Therefore, a very good comprehensive performance was reflected on the macro properties.

\section{Conclusions}

When NCC was modified by KH550, NR/MNCC/ silica compounds showed an accelerated curing rate, reduced Payne effect and better processing performance. Tear strength, 300\% modulus, hardness, heat build-up, compression set and dynamic mechanical performance of NR/MNCC/silica nanocomposites were greatly improved. MNCC and $\mathrm{NR} /$ silica compatibility was reinforced. Meanwhile, the apparent crosslinking density analysis, TGA, TEM and SEM images show the dispersion of in the matrix and interfacial strength of between MNCC and $\mathrm{NR} /$ silica nanocomposites was enhanced. In addition, a number of advantages such as renewable, biodegradable, broadly obtained, low density, low-cost and environmentally friendly, make NCC become a new energy saving filler to partly replace silica.

\section{Acknowledgements}

The authors would like to acknowledge the support of the National Natural Science Foundation of China (51173046). 


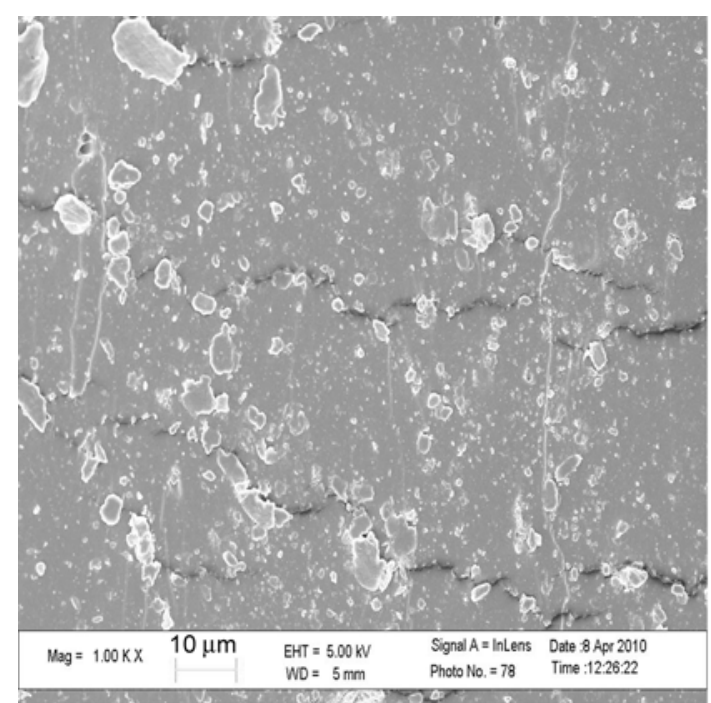

a)

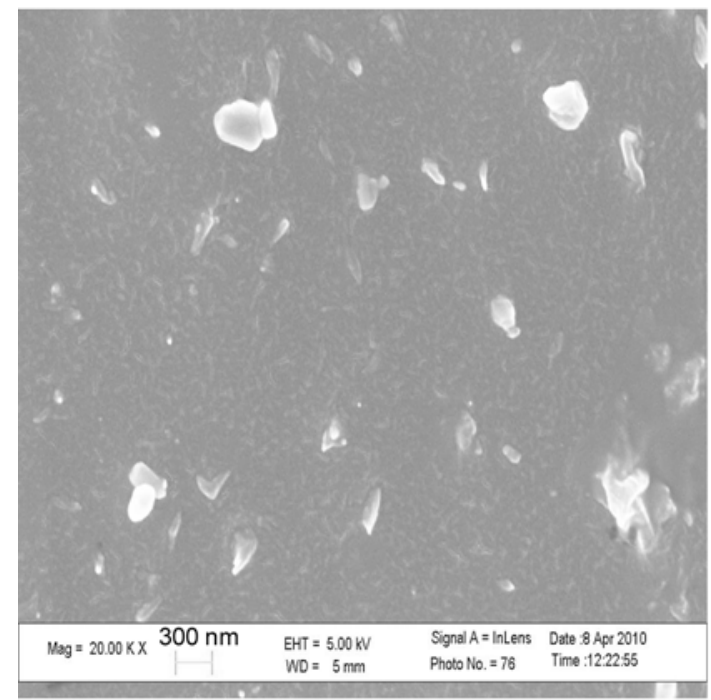

c)

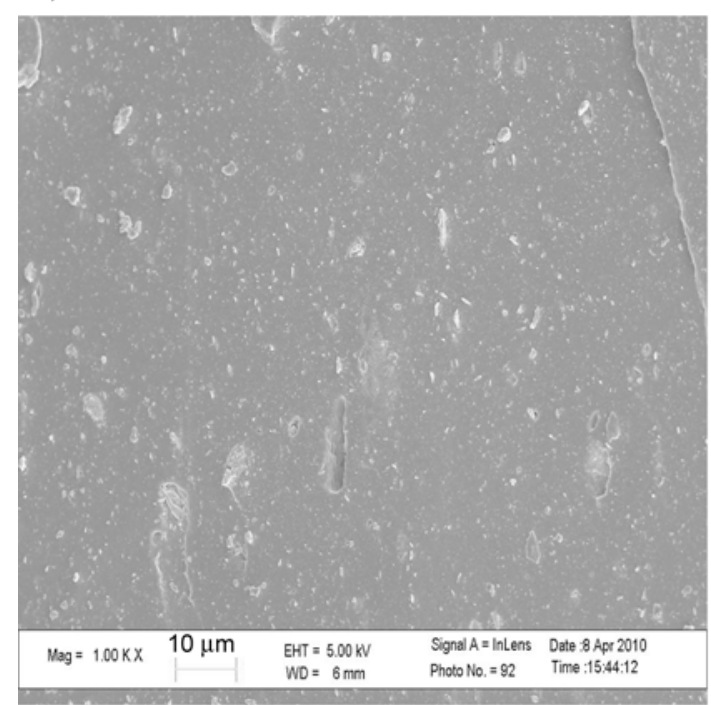

e)

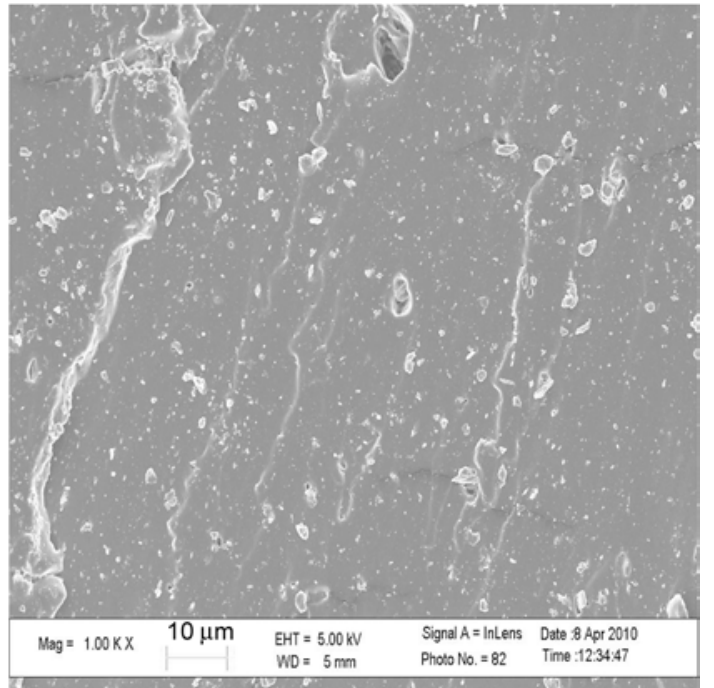

b)

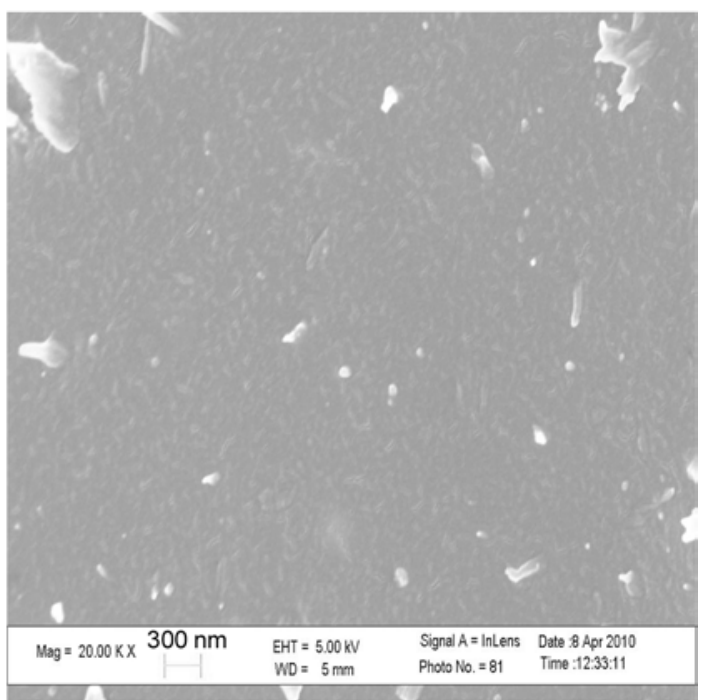

d)

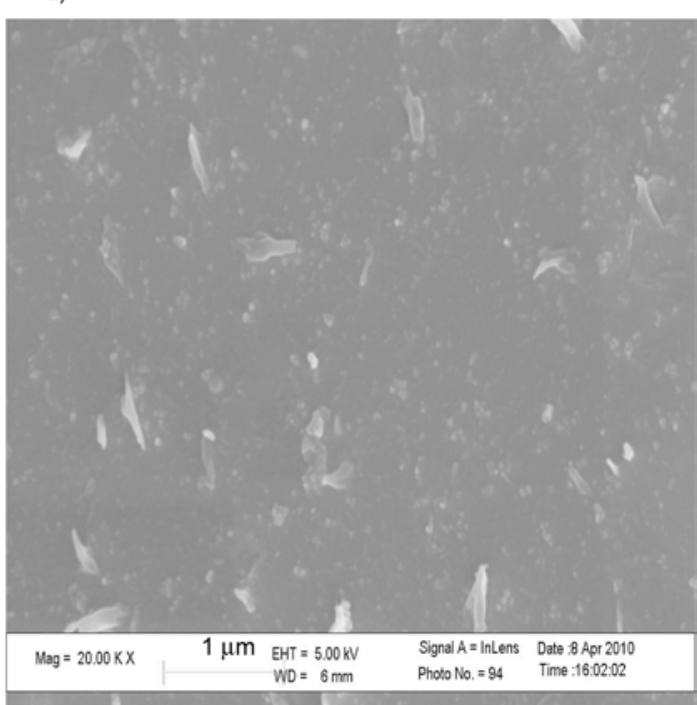

f)

Figure 9. SEM micrographs of stretch broken surface of the (a, c) NR/NCC (100/10), (b, d) NR/MNCC (100/10) and (e, f) NR/MNCC/silica (100/10/20) nanocomposites 


\section{References}

[1] Castellano M., Conzatti L., Costa G., Falqui L., Turturro A., Valenti B., Negroni F.: Surface modification of silica: 1 . Thermodynamic aspects and effect on elastomer reinforcement. Polymer, 46, 695-703 (2005). DOI: 10.1016/j.polymer.2004.11.010

[2] Bokobza L., Chauvin J-P.: Reinforcement of natural rubber: Use of in situ generated silicas and nanofibres of sepiolite. Polymer, 46, 4144-4151 (2005). DOI: $10.1016 /$ j.polymer.2005.02.048

[3] Ansarifar A., Wang L., Ellis R. J., Haile-Meskel Y.: Using a silanized silica nanofiller to reduce excessive amount of rubber curatives in styrene-butadiene rubber. Journal of Applied Polymer Science, 119, 922928 (2011).

DOI: $10.1002 /$ app.32772

[4] Esch H., Goerl U., Kuhlmann R., Rausch R.: Precipitated silicas. European Patent 0647591, Germany (1995).

[5] Rattanasom N., Prasertsri S., Ruangritnumchai T.: Comparison of the mechanical properties at similar hardness level of natural rubber filled with various reinforcing-fillers. Polymer Testing, 28, 8-12 (2009).

DOI: $10.1016 /$ j.polymertesting.2008.08.004

[6] Peng H., Liu L., Luo Y., Wang X., Jia D.: Effect of 3propionylthio-1-propyltrimethoxylsilane on structure, mechanical, and dynamic mechanical properties of NR/silica composites. Polymer Composites, 30, 955961 (2009).

DOI: $10.1002 /$ pc. 20640

[7] Stöckelhuber K. W., Das A., Jurk R., Heinrich G.: Contribution of physico-chemical properties of interfaces on dispersibility, adhesion and flocculation of filler particles in rubber. Polymer, 51, 1954-1963 (2010).

DOI: $10.1016 /$ j.polymer.2010.03.013

[8] Qi Q., Wu Y., Tian M., Liang G., Zhang L., Ma J.: Modification of starch for high performance elastomer. Polymer, 47, 3896-3903 (2006).

DOI: $10.1016 /$ j.polymer.2006.03.095

[9] Liu C., Shao Y., Jia D.: Chemically modified starch reinforced natural rubber composites. Polymer, 49, 2176-2181 (2008).

DOI: $10.1016 /$ j.polymer.2008.03.005

[10] Favier V., Chanzy H., Cavaille J. Y.: Polymer nanocomposites reinforced by cellulose whiskers. Macromolecules, 28, 6365-6367 (1995).

DOI: $10.1021 / \mathrm{ma} 00122 \mathrm{a} 053$

[11] Nair K. G., Dufresne A.: Crab shell chitin whisker reinforced natural rubber nanocomposites. 1. Processing and swelling behavior. Biomacromolecules, 4, 657-665 (2003).

DOI: $10.1021 / \mathrm{bm} 020127 \mathrm{~b}$

[12] Nair K. G., Dufresne A.: Crab shell chitin whisker reinforced natural rubber nanocomposites. 2. Mechanical behavior. Biomacromolecules, 4, 666-674 (2003). DOI: $10.1021 / \mathrm{bm} 0201284$
[13] Gu J., Li X-H., Jia D-M., Luo Y-F., Cheng R-S.: Reinforcement of natural cellulose whisker on natural rubber. Acta Polymerica Sinica, 7, 595-598 (2007).

DOI: 10.3724/SP.J.1105.2009.00595

[14] Bai W., Li K.: Partial replacement of silica with microcrystalline cellulose in rubber composites. Composites Part A: Applied Science and Manufacturing, 40, 15971605 (2009).

DOI: 10.1016/j.compositesa.2009.07.006

[15] Nair K. G., Dufresne A., Gandini A., Belgacem M. N.: Crab shell chitin whiskers reinforced natural rubber nanocomposites. 3. Effect of chemical modification of chitin whiskers. Biomacromolecules, 4, 1835-1842 (2003). DOI: 10.1021/bm030058g

[16] Bendahou A., Kaddami H., Dufresne A.: Investigation on the effect of cellulosic nanoparticles' morphology on the properties of natural rubber based nanocomposites. European Polymer Journal, 46, 609-620 (2010). DOI: 10.1016/j.eurpolymj.2009.12.025

[17] Samir M. A. S. A., Alloin F., Dufresne A.: Review of recent research into cellulosic whiskers, their properties and their application in nanocomposite field. Biomacromolecules, 6, 612-626 (2005). DOI: $10.1021 / \mathrm{bm} 0493685$

[18] Eichhorn S. J., Dufresne A., Aranguren M., Marcovich N. E., Capadona J. R., Rowan S. J., Weder C., Thielemans W., Roman M., Renneckar S., Gindl W., Veigel S., Keckes J., Yano H., Abe K., Nogi M., Nakagaito A. N., Mangalam A., Simonsen J., Benight A. S., Bismarck A., Berglund L. A., Peijs T.: Review: Current international research into cellulose nanofibres and nanocomposites. Journal of Materials Science, 45, 1-33 (2010). DOI: $10.1007 / \mathrm{s} 10853-009-3874-0$

[19] Ljungberg N., Bonini C., Bortolussi F., Boisson C., Heux L., Cavaillé J. Y.: New nanocomposite materials reinforced with cellulose whiskers in atactic polypropylene: Effect of surface and dispersion characteristics. Biomacromolecules, 6, 2732-2739 (2005).

DOI: $10.1021 / \mathrm{bm} 050222 \mathrm{v}$

[20] Ljungberg N., Cavaillé J-Y., Heux L.: Nanocomposites of isotactic polypropylene reinforced with rod-like cellulose whiskers. Polymer, 47, 6285-6292 (2006). DOI: $10.1016 /$ j.polymer.2006.07.013

[21] Berlioz S., Molina-Boisseau S., Nishiyama Y., Heux L.: Gas-phase surface esterification of cellulose microfibrils and whiskers. Biomacromolecules, 10, 2144-2151 (2009). DOI: $10.1021 / \mathrm{bm} 900319 \mathrm{k}$

[22] Braun B., Dorgan J. R.: Single-step method for the isolation and surface functionalization of cellulosic nanowhiskers. Biomacromolecules, 10, 334-341 (2009). DOI: 10.1021/bm8011117

[23] Goussé C., Chanzy H., Excoffier G., Soubeyrand L., Fleury E.: Stable suspensions of partially silylated cellulose whiskers dispersed in organic solvents. Polymer, 43, 2645-2651 (2002). DOI: $10.1016 / \mathrm{S} 0032-3861(02) 00051-4$ 
[24] Yuan H., Nishiyama Y., Wada M., Kuga S.: Surface acylation of cellulose whiskers by drying aqueous emulsion. Biomacromolecules, 7, 696-700 (2006). DOI: $10.1021 / \mathrm{bm} 050828 \mathrm{j}$

[25] de Menezes A. J., Siqueira G., Curvelo A. A. S., Dufresne A.: Extrusion and characterization of functionalized cellulose whiskers reinforced polyethylene nanocomposites. Polymer, 50, 4552-4563 (2009). DOI: $10.1016 /$ j.polymer.2009.07.038

[26] Yi J., Xu Q., Zhang X., Zhang H.: Chiral-nematic selfordering of rodlike cellulose nanocrystals grafted with poly(styrene) in both thermotropic and lyotropic states. Polymer, 49, 4406-4412 (2008).

DOI: $10.1016 /$ j.polymer.2008.08.008

[27] Ljungberg N., Cavaillé J-Y., Heux L.: Nanocomposites of isotactic polypropylene reinforced with rod-like cellulose whiskers. Polymer, 47, 6285-6292 (2006). DOI: $10.1016 /$ j.polymer.2006.07.013

[28] Lu J., Askeland P., Drzal L. T.: Surface modification of microfibrillated cellulose for epoxy composite applications. Polymer, 49, 1285-1296 (2008). DOI: 10.1016/j.polymer.2008.01.028

[29] Chang C., Duan B., Zhang L.: Fabrication and characterization of novel macroporous cellulose-alginate hydrogels. Polymer, 50, 5467-5473 (2009). DOI: 10.1016/j.polymer.2009.06.001

[30] Cao X., Dong H., Li C. M.: New nanocomposite materials reinforced with flax cellulose nanocrystals in waterborne polyurethane. Biomacromolecules, 8, 899904 (2007).

DOI: $10.1021 / \mathrm{bm} 0610368$
[31] Ten E., Turtle J., Bahr D., Jiang L., Wolcott M.: Thermal and mechanical properties of poly(3-hydroxybutyrate-co-3-hydroxyvalerate)/cellulose nanowhiskers composites. Polymer, 51, 2652-2660 (2010).

DOI: 10.1016/j.polymer.2010.04.007

[32] Wang N., Ding E., Cheng R.: The surface modification of nanocrystalline cellulose. Acta Polymerica Sinica, 8, 982-987 (2006). DOI: $10.3724 /$ SP.J.1105.2006.00982

[33] Liu L., Jia D., Luo Y., Guo B.: Preparation, structure and properties of nitrile-butadiene rubber-organoclay nanocomposites by reactive mixing intercalation method. Journal of Applied Polymer Science, 100, 1905-1913 (2006).

DOI: 10.1002/app.22614

[34] Haghighat M., Zadhoush A., Khorasani S. N.: Physicomechanical properties of $\alpha$-cellulose-filled styrenebutadiene rubber composites. Journal of Applied Polymer Science, 96, 2203-2211 (2005).

DOI: 10.1002/app.21691

[35] Maridass B., Gupta B. R.: Effect of carbon black on devulcanized ground rubber tire-natural rubber vulcanizates: Cure characteri stics and mechanical properties. Journal of Elastomers and Plastics, 38, 211-229 (2006).

DOI: $10.1177 / 0095244306063480$

[36] Wolff S., Wang M. J., Tan E. H.: Surface-energy of fillers and its effect on rubber reinforcement, 1. Kautschuk und Gummi Kunststoffe, 47, 780-798 (1994).

[37] Bondeson D., Mathew A., Oksman K.: Optimization of the isolation of nanocrystals from microcrystalline cellulose by acid hydrolysis. Cellulose, 13, 171-180 (2006). DOI: $10.1007 / \mathrm{s} 10570-006-9061-4$ 